Acknowledgment. This work was supported by the National Science Foundation and the Camille and Henry Dreyfus Foundation through their Presidential Young Investigator Award and Distinguished New Faculty Award programs, respectively (E. A.C.). We thank G. B. Ellison for stimulating us to carry out this work and $\mathbf{P}$. Taylor for communicating results prior to publication.

\section{New Aspects of Chiral Heteroorganocuprates and an X-ray Crystal Structure with Unprecedented Magnesium-Sulfur Bonds}

D. Martin Knotter ${ }^{1 \mathrm{a}}$ Wilberth J. J. Smeets, ${ }^{1 \mathrm{~b}}$ Anthony L. Spek, ${ }^{16}$ and Gerard van Koten*,la

\section{Debye Research Institute \\ Department of Metal-Mediated Synthesis University of Utrecht, Padualaan 8 $3584 \mathrm{CH}$ Utrecht, The Netherlands Laboratory of Crystal and Structural Chemistry University of Utrecht, Padualaan 8 3584 CH Utrecht, The Netherlands \\ Received May 1, 1990}

Heterocuprates with both transferable groups (e.g., alkyl and aryl anions) and nontransferable groups (e.g., cyanide and thiolate anions) are excellent reagents for the formation of new $\mathrm{C}-\mathrm{C}$ bonds in organic synthesis. ${ }^{2,3}$ Although some information concerning the structural features of homocuprates in the solid state ${ }^{4 a}$ and in solution is available, ${ }^{4}$ little is known about the nature of heterocuprates. In the course of our study directed to the rational synthesis of chiral heterocuprates having well-defined stoichiometries, we recently reacted both $\mathrm{LiC} \equiv \mathrm{C}-{ }^{-} \mathrm{Bu}$ and $\mathrm{CuC} \equiv \mathrm{C}_{-}^{-} \mathrm{Bu}$ with the novel, trimeric copper(I) thiophenolate, $\left[\mathrm{CuSC}_{6} \mathrm{H}_{4}(\mathrm{CH}-\right.$ $\left.\left.(\mathrm{Me}) \mathrm{NMe}_{2}\right)-2\right]_{3}\left(1 ;[\mathrm{CuSAr}]_{3}\right)$, which has intramolecular $\mathrm{Cu}-\mathrm{N}$ coordination as a special feature. ${ }^{3}$ Surprisingly, in both reactions a mixed organo-thiophenolato copper compound, $\left[\mathrm{Cu}_{3}(\mathrm{SAr})_{2}-\right.$ $\left.\left(\mathrm{C} \equiv \mathrm{C}-{ }^{\mathrm{B}} \mathrm{Bu}\right)\right]_{2}$, was formed quantitatively. ${ }^{6}$ In the reaction of 1 with $\mathrm{LiC} \equiv \mathrm{C}$ - ${ }^{-} \mathrm{Bu}$ an alkynyl-thiophenolate anion exchange has occurred to generate this heteroorganocopper compound and a lithium thiophenolate rather than the expected heterocuprate.

We now report that whereas the reaction of 1 with dimesitylmagnesium affords a unique heterocuprate, 2 , its reaction with mesitylcopper as organometallic reagent affords a heteroorganocopper compound 3 (see Scheme I).

A mixture of [CuSAr] $]_{3}$ (1) $(3.68 \mathrm{mmol})$ and $\left[\mathrm{Mg}(\mathrm{Mes})_{2}-\right.$ $(\mathrm{THF})_{2}$ ] ( $5.54 \mathrm{mmol} ; 0.5$ equiv/ $\mathrm{Cu}$ ) was dissolved in $75 \mathrm{~mL}$ of boiling toluene. Distillation was used to remove the THF and to concentrate the reaction solution to $65 \mathrm{~mL}$. On cooling of the solution to room temperature, the new heterocuprate $\left[(\mathrm{CuMes})_{4}(\mu-\mathrm{SAr})_{2}(\mathrm{MgSAr})_{2}\right]$ (2) crystallized out as pale yellow crystals $(73 \%)$.

The heteroorganocopper compound $\left[\mathrm{Cu}_{2}(\mathrm{SAr})(\mathrm{Mes})\right]_{2}(3)$ was formed from the reaction of $1(2.21 \mathrm{~g} ; 9.09 \mathrm{mmol}$ of $\mathrm{Cu})$ with [CuMes] ${ }_{5}^{7}(1.66 \mathrm{~g}: 9.09 \mathrm{mmol}$ of $\mathrm{Cu})$ in $25 \mathrm{~mL}$ of benzene at

- To whom correspondence should be addressed.

(1) (a) Debye Research Institute. (b) Laboratory of Crystal and Structural Chemistry.

(2) (a) Lipshutz, B. H. Synthesis 1987, 325. (b) Posner, G. H. An Introduction to Synthesis using Organocopper Reagents; Wiley-Interscience: New York, 1980. (c) Normant, J. F. Synthesis 1972, 63.

(3) (a) Leyendecker, F.; Laucher, D. Nouv. J. Chim. 1985, 9, 13. (b) Villacorta, G. M.; Pulla, C.; Lippard, S. J. J. Am. Chem. Soc. 1988, 110, 3175. (c) Corey, E.; Naef, R.; Hannon, F. Ibid. 1986, 108, 7114

(4) (a) Lorenzen, N. P.; Weiss, E. Angew. Chem. 1990, 102, 322; Angew. Chem., Int. Ed. Engl. 1990, 29, 300. (b) Olmstead, M. M.; Power, P. P. J. Am. Chem. Soc., 1989, $/ 11,4135$. (c) Khan, S. I.; Edwards, P. G.; Yuan, H. S. H.; Bau, R. Ibid. 1985, 107, 1682. (d) van Koten, G.; Jastrzebski, J. T. B. H. Ibid. 1985, 107, 697. (e) Hope, H.; Oram, D.; Power, P. P. Ibid. 1984, 106, 1149

(5) Knotter, D. M.; van Koten, G.; van Maanen, H. L.; Grove, D. M.; Spek, A. L. Angew. Chem. 1989, 101, 351; Angew. Chem., Int. Ed. Engl. 1989, 28,341

(6) Knotter, D. M.; Spek, A. L.; van Koten, G. J. Chem. Soc., Chem. Commun. 1989, 1738

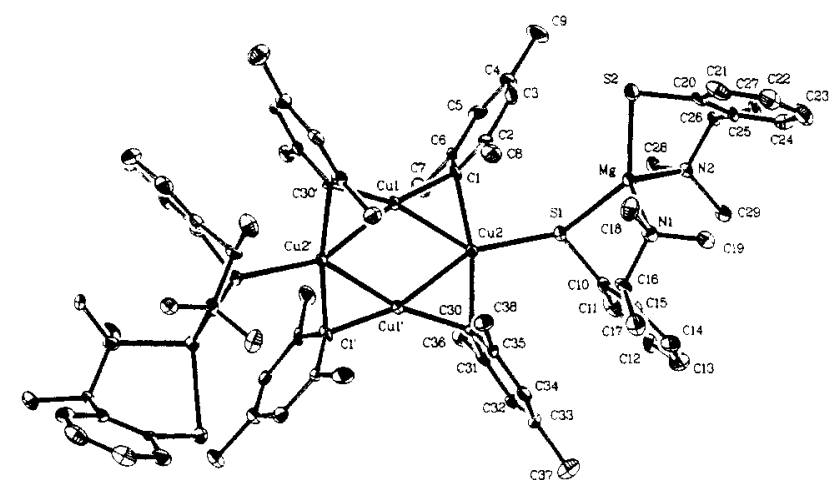

Figure 1. ORTEP drawing ( $50 \%$ probability level) of $\left[\right.$ (CuMes) ${ }_{4}(\mu$ SAr) $\left.{ }_{2}(\mathrm{MgSAr})_{2}\right]$ (2). Selected bond lengths $(\AA)$ and angles (deg): $\mathrm{Cu} 1-\mathrm{Cl}, 1.981$ (8); $\mathrm{Cu} 1-\mathrm{C} 30^{\circ}, 2.025(8) ; \mathrm{Cu} 2-\mathrm{Cl}, 2.064(8) ; \mathrm{Cu} 2-\mathrm{C} 30$, 2.044 (8); Cu2-S1, 2.389 (2); Mg-N1, 2.186 (8); Mg-N12, 2.180 (7); $\mathrm{Cu} 1 \ldots \mathrm{Cu} 1^{\prime}, 2.700$ (1); Cul...Cu2, 2.464 (1); Cul...Cu2', 2.431 (1); $\mathrm{Cu} 2 \ldots \mathrm{Cu} 2^{\prime}, 4.079$ (1); Cul-C1-Cu2, 75.0 (3), Cul'-C30-Cu2, 73.4 (3); $\mathrm{Cu} 2-\mathrm{S} 1-\mathrm{Mg}, 136.4$ (1); S1-Mg-S2, 132.5 (2); N1-Mg-N2, 116.4 (3); $\mathrm{S} 1-\mathrm{Mg}-\mathrm{N} 1,95.8(2) ; \mathrm{S} 2-\mathrm{Mg}-\mathrm{N} 2,95.9$ (2)

room temperature and was obtained as a yellow solid after the solvent was distilled off. On the basis of ${ }^{1} \mathrm{H}$ NMR spectroscopic results, molecular weight determination (cryoscopy in benzene), and microwave titration of mesitylcopper with 1 (equivalence point at a 1:1 molar ( $\mathrm{Cu}$ ) ratio), we conclude that 3 exists in solution as a tetranuclear copper compound $\left[\mathrm{Cu}_{2}(\mathrm{Mes})(\mathrm{SAr})\right]_{2}{ }^{8}$ Moreover, 'H NMR studies of 3 in solution showed it to be a stable, discrete compound which does not undergo exchange with excess of either [CuSAr] ${ }_{3}$ or mesitylcopper.

Recrystallization of $\left[(\mathrm{CuMes})_{4}(\mu \text {-SAr })_{2}(\mathrm{MgSAr})_{2}\right](2)$ from toluene gave crystals of a toluene solvate that were suitable for an X-ray structure determination. ${ }^{9}$ The molecular structure found, shown in Figure 1, reveals 2 to be a heterocuprate with a structure consisting of a tetranuclear mesitylcopper unit bound to two bis(thiophenolato)magnesium units. The most noteworthy aspect is the presence of $\mathrm{Mg}-\mathrm{S}$ bonds; one thiophenolate unit is $\mathrm{S}, \mathrm{N}$ chelated to the magnesium center, and the other ( $\mathrm{N}$ bound to $\mathrm{Mg}$ ) uses its sulfur atom to bridge between copper and magnesium. Furthermore, this structure shows that during the synthesis complete exchange of thiophenolate and mesityl groups between copper and magnesium has occurred.

The overall structure of the central tetranuclear arylcopper unit in 2 is comparable to those of $\left[\mathrm{Cu}_{4}(\mathrm{Mes})_{4}(\mathrm{THT})_{2}\right]$ (THT $=$ tetrahydrothiophene) ${ }^{10}$ and the $o$-tolylcopper compound $\left[\mathrm{CH}_{4}-\right.$ $\left.\left(\mathrm{C}_{6} \mathrm{H}_{4} \mathrm{Me}-2\right)_{4}\left(\mathrm{SMe}_{2}\right)_{2}\right]^{11}$ The four copper atoms in 2 are almost coplanar with $\mathrm{Cu} \cdots \mathrm{Cu}$ distances $(2.431$ (1) and 2.464 (1) $\AA$ ) that

(7) Tsuda, T.; Yazawe, T.; Watanabe, T.; Fujii, T.; Saegusa, T. J. Org. Chem. 1981, 46, 142.

(8) Molecular weight (cryoscopy in the concentration range of 105-25.6 $\mathrm{g} \mathrm{kg}^{-1}$ benzene): $813 \mathrm{~g} \mathrm{~mol}^{-1}$ (calcd for [Cu $\left.\mathrm{Cu}_{2}(\mathrm{SAr})(\mathrm{Mes})\right]_{2}(3): 850 \mathrm{~g} \mathrm{~mol}^{-1}$ ) $f_{\mathrm{H}} \mathrm{NMR}$ (toluene- $\left.d_{8}, 233 \mathrm{~K}\right): \delta 1.12\left(\mathrm{~s}, 3 \mathrm{H}, \mathrm{NCH}_{3}\right), 1.54(\mathrm{~d}, 3 \mathrm{H}$, $\left.\mathrm{ArCCH}_{3}\right), 1.71\left(\mathrm{~s}, 3 \mathrm{H}, \mathrm{NCH}_{3}\right), 2.11\left(\mathrm{~s}, 3 \mathrm{H}, \mathrm{p}\right.$-Mes-CH $\mathrm{CH}_{3}, 2.33(\mathrm{~s}, 3 \mathrm{H}$, o-Mes-CH $)_{3}, 2.63$ (q, $\left.1 \mathrm{H}, \mathrm{HCMe}\right), 2.82$ (s, $\left.3 \mathrm{H}, \mathrm{o}-\mathrm{Mes}-\mathrm{CH}_{3}\right), 6.53(\mathrm{~s}, 1 \mathrm{H}$, H-Mes), 6.61 (d, I H, 3-H-ArS), $6.82(\mathrm{~s}, 1 \mathrm{H}, \mathrm{H}$-Mes), 6.91 (dt, $1 \mathrm{H}$, 4-H-ArS), 7.06 (dt, 1 H, 5-H-ArS), 7.93 (d, 1 H, 6-H-ArS)

(9) Crystal data for 2: $\mathrm{C}_{76} \mathrm{H}_{100} \mathrm{Cu}_{4} \mathrm{Mg}_{2} \mathrm{~N}_{4} \mathrm{~S}_{4} \cdot 2 \mathrm{C}_{7} \mathrm{H}_{8}$, rod-shaped crystal $(0.08 \times 0.13 \times 0.90 \mathrm{~mm})$, orthorhombic, space group $P 2_{1} 2_{1} 2$, with $a=25.140$ (3) $\AA, b=19.026(2) \AA, c=8.554$ (1) $\AA, V=4091.5(8) \AA^{3}, Z=2, d_{\text {ala }}$ $=1.368 \mathrm{~g} \mathrm{~cm}^{-3}, F(000)=1776, \mu(\mathrm{Mo} \mathrm{K} \alpha)=11.9 \mathrm{~cm}^{-1} ; 6236$ independent reflections $\left(0.81<\theta<29.4^{\circ} ; \omega / 2 \theta\right.$-scan; $\left.T=100 \mathrm{~K}\right)$ were measured on an Enraf-Nonius CAD-4F diffractometer using $\mathrm{Zr}$-filtered Mo $\mathrm{K} \alpha$ radiation $(\lambda$ $=0.71073 \AA$ ). Data were corrected for Lorentz polarization effects and for a small linear decay $(0.4 \%)$. The structure was solved by Patterson (SHELXS 86) and difference Fourier techniques and refined by full-matrix least squares (SHELX 76) to an $R$ value of $0.056, w R=0.061, w^{-1}=\left(\sigma^{2}(F)+0.00106 F^{2}\right)$ for 3674 reflections with $I>2.5 \sigma(I)$. Hydrogen atoms were introduced on calculated positions and refined riding on their carrier atoms. All non-H atoms were refined with anisotropic thermal parameters. A final difference Fourier map showed no residual density outside 0.90 and $-0.58 \mathrm{e} / \AA^{3}$ (near the $C u$ atoms). Geometrical details of the structure are provided as supplementary material.

(10) Meyers, E. M.; Gambarotta, S.; Floriani, C.; Chiesi-Villa, A.; Guastini, C. Organometallics 1989, 8, 1067

(I1) Lenders, B.; Smeets, W. J. J.; van der Sluis, P.; Grove, D. M.; Spek, A. L.; van Koten, G. Organometallics. Accepted for publication. 
Scheme $I^{a}$

$$
\begin{aligned}
& {\left[(\mathrm{CuMes})_{4}(\mu-\mathrm{SAr})_{2}(\mathrm{MgSAr})_{2}\right](2)} \\
& {\left[\mathrm{Mg}(\mathrm{Mes})_{2}(\mathrm{THF})_{2}\right]} \\
& \text { [CuSAr] }]_{3} \text { (1) } \\
& {[\text { CuMes }]_{5}} \\
& {\left[\mathrm{Cu}_{2}(\mathrm{SAr})(\mathrm{Mes})\right]_{2} \text { (3) }}
\end{aligned}
$$

${ }^{a} \mathrm{SAr}=\mathrm{SC}_{6} \mathrm{H}_{4}\left(\mathrm{CH}(\mathrm{Me}) \mathrm{NMe}_{2}\right)-2$. Mes $=\mathrm{C}_{6} \mathrm{H}_{2} \mathrm{Me}_{3}-2,4,6$.

are typical for three-center two-electron carbon-bridged copper atoms. The shortest $\mathrm{Cu}$... Cu distance of 2.700 (1) $\AA$ across the $\mathrm{Cu}_{4}$ array in $2\left(\mathrm{Cul}-\mathrm{Cul}^{\prime}\right)$ is $0.1 \AA$ longer than the comparable feature in the structure of $\left[\mathrm{Cu}_{4}(\mathrm{Mes})_{4}(\mathrm{THT})_{2}\right]$. The central mesitylcopper unit in 2 contains two two-coordinate copper atoms $\left(\mathrm{Cl}-\mathrm{Cl}-\mathrm{C} 30^{\prime}=142.8(3)^{\circ}\right)$ and two planar three-coordinate copper atoms $\left(\mathrm{C} 1-\mathrm{Cu} 2-\mathrm{C} 30=168.1(3)^{\circ}, \mathrm{S} 1-\mathrm{Cu} 2-\mathrm{Cl}=90.0\right.$ $(2)^{\circ}, \mathrm{S} 1-\mathrm{Cu} 2-\mathrm{C} 30=101.4(2)^{\circ}$ )

For the sulfur atom $\mathrm{S} 1$ bridging between $\mathrm{Cu} 2$ and magnesium, there are two extreme bonding descriptions possible that necessarily affect our view of the nature of complex 2. In one description (Figure 2a) there is a tetranuclear organocopper unit, [CuMes] ${ }_{4}$, to which two $\mathrm{Mg}(\mathrm{SAr})_{2}$ units are connected through thiolate $\mathrm{S}$ $\rightarrow \mathrm{Cu}$ donative coordination. This situation is analogous to the coordination of the THT molecule in the organocopper complex $\left[\mathrm{Cu}_{4}(\mathrm{Mes})_{4}(\mathrm{THT})_{2}\right]$. The second description (Figure $2 \mathrm{~b}$ ) of 2 is based on an ionic structure containing a $\left[\mathrm{Cu}_{4} \mathrm{Mes}_{4}(\mathrm{SAr})_{2}\right]^{2-}$ anion with two $[\mathrm{MgSAr}]^{+}$cations, each of which is bonded to a thiolato sulfur atom of the cuprate by a $\mathrm{S} \rightarrow \mathrm{Mg}$ bond. The X-ray data do not allow us to readily discriminate between these two descriptions.

There are no experimental geometries available for $\mathrm{MgSR}^{+}$ or $\mathrm{Mg}\left(\mathrm{SR}_{2}\right)^{2+}$ units in which a sulfur atom is bound to a magnesium ion. The $\mathrm{Mg}-\mathrm{S}$ bond lengths in 2 are 2.375 (4) $\AA$ for $\mathrm{S} 2$ of the chelate and 2.427 (4) $\AA$ for S1 of the bridge, and the bond angles $\mathrm{Mg}-\mathrm{S}-\mathrm{Ar}$ are $89.5(3)^{\circ}$ and $89.7(3)^{\circ}$, respectively. These values give support to $a b$ initio calculations carried out by Pappas on $\mathrm{Mg}(\mathrm{SH})^{+}$and $\mathrm{Mg}(\mathrm{SH})_{2}$ that gave $\mathrm{Mg}-\mathrm{S}$ bond distances of 2.264 and $2.324 \AA$, respectively, ${ }^{12}$ and a $\mathrm{Mg}-\mathrm{S}-\mathrm{H}$ bond angle of $95.2^{\circ}$.

In the bridging thiophenolate group of 2 the $\mathrm{Cu} 2-\mathrm{S} 1-\mathrm{C} 10$ bond angle is $120.1(3)^{\circ}$ and the $\mathrm{Mg}-\mathrm{S} 1-\mathrm{C} 10$ bond angle is approximately $90^{\circ}$. These bond angles lead us to the conclusion that the sulfur atom is most likely $\mathrm{sp}^{2}$ hybridized. The magnesium ion is bound through a sulfur $\mathrm{p}_{z}$ orbital, while the copper atom $(\mathrm{Cu} 2)$ and the carbon atom $(\mathrm{C} 10)$ are bound through two $\mathrm{sp}^{2}$ orbitals of sulfur. The use of the sulfur $\mathrm{p}_{2}$ orbital to form the $\mathrm{Mg}-\mathrm{S}$ bond is logical since this orbital is anticipated to have higher electron density than the $\mathrm{sp}^{2}$ orbital and it is therefore a harder Lewis base. ${ }^{13}$ Compared to $\mathrm{Mg}^{2+}$, the $\mathrm{Cu}^{+}$cation is a softer Lewis acid and prefers binding to the softer Lewis base $\mathrm{sp}^{2}$ hybrid orbital of the sulfur atom. We think that the bonding of the sulfur atom $\mathrm{S} 2$ of the chelating thiophenolate also occurs through its $\mathrm{p}_{2}$ orbital ( $\mathrm{Mg} 1-\mathrm{S} 2-\mathrm{C} 20 \cong 90^{\circ}$ ).

For the bridging sulfur atom $\mathrm{Sl}$ the $\mathrm{Cu} 2-\mathrm{S} 1-\mathrm{Mg}$ bond angle of $136.4(1)^{\circ}$ is much larger than the $90^{\circ}$ that might be expected when copper is bound through an $\mathrm{sp}^{2}$ orbital and magnesium is bound through a $\mathrm{p}_{z}$ orbital. There are several possible explanations for this discrepancy. One reason could be the presence of Coulombic repulsion between the $\mathrm{Cu}^{+}$and $\mathrm{Mg}^{2+}$ cations. A second explanation is that the sulfur atom $\mathrm{S} 1$ is bridging between copper and magnesium ion by means of a four-electron three-center bond without any direct metal-metal interaction. Consequently, the copper-magnesium distance of 4.472 (3) $\AA$ is much longer than that in the cuprate $\left[\mathrm{Cu}_{4} \mathrm{MgPh}_{6} \cdot \mathrm{OEt}_{2}\right](2.754 \AA)$ where the same metal ions are bridged by a carbon atom with a two-electron

(12) Pappas, J. A. J. Am. Chem. Soc. 1978, 100, 6023.

(13) (a) Coppens, P.; Yang, Y. W.; Blessing, R. H.; Cooper, W. F.; Larsen, F. K. J. Am. Chem. Soc. 1977, 99, 760. (b) Guru Row, T. N.; Parthasarathy, R. Ibid. 1981, 103, 477.
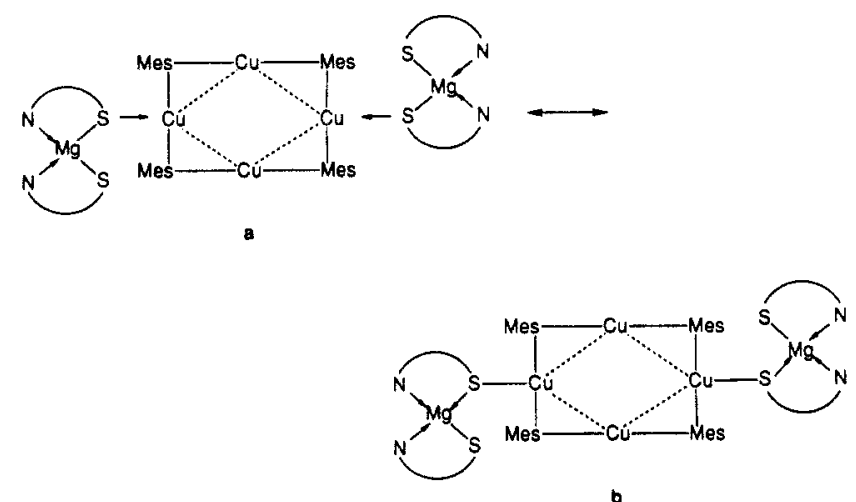

Figure 2. Schematic structure of $\left[(\mathrm{CuMes})_{4}(\mu-\mathrm{SAr})_{2}(\mathrm{MgSAr})_{2}\right]$ (2) with donative coordination of the bridging sulfur $(\mu-\mathrm{SAr})$ (a) to a copper atom or (b) to a magnesium atom.

three-center bond which assists the metal-metal interaction..$^{4 b}$ Steric reasons for the large $\mathrm{Cu}-\mathrm{S}-\mathrm{Mg}$ angle cannot be excluded, either.

Currently the structure in solution of $\left[(\mathrm{CuMes})_{4}(\mu-\mathrm{SAr})_{2}-\right.$ $\left.(\mathrm{MgSAr})_{2}\right](2)$ is being studied by ${ }^{1} \mathrm{H}$ NMR spectroscopy (toluene- $d_{8}$ ). Preliminary results indicate that dissolved 2 breaks up into various species. By comparison with the ${ }^{1} \mathrm{H}$ NMR shifts of authentic samples, some of the species could be identified as 3 , $[\mathrm{CuMes}]_{4}$, and $\left[\mathrm{Mg}(\mathrm{SAr})_{2}\right]$. Further studies are needed to substantiate that the interaction found between [CuMes $]_{4}$ and $\left[\mathrm{Mg}(\mathrm{SAr})_{2}\right]$ in the solid state is also present in solution. The use of 2 and 3 in 1,4-conjugated addition reactions to $\alpha, \beta$-unsaturated ketones is under investigation.

Acknowledgment. This work was supported in part (A.L.S. and W.J.J.S.) by the Netherlands Foundation for Chemical Research (SON) with financial aid from the Netherlands Organization for Scientific Research (NWO).

Supplementary Material Available: Tables of fractional coordinates of all atoms, bond distances and angles, and anisotropic thermal parameters for 2 (8 pages); listing of observed and calculated structure factor amplitudes for 2 (38 pages). Ordering information is given on any current masthead page.

\section{Nuclear Overhauser Effect in Solids}

Jeffery L. White and James F. Haw*

Department of Chemistry, Texas A\&M University College Station, Texas 77843

Received April 3, 1990

In 1953, Carver and Slichter ${ }^{1}$ confirmed the predictions of Overhauser ${ }^{2}$ concerning polarization transfer from the conduction electrons of metals to nuclear spins upon saturation of the electron resonance. The nuclear Overhauser effect (NOE), as it has come to be known, has been exploited primarily in solution NMR for sensitivity enhancement, spectral assignment, and conformational analysis. ${ }^{3,4}$ Curiously, with the popularization of solid-state NMR techniques through line-narrowing methods such as magic-angle spinning (MAS), the potential for exploitation of the NOE in solids has not been fully explored. This neglect is likely due to the widely

Author to whom correspondence should be addressed.

(1) (a) Carver, T. R.; Slichter, C. P. Phys. Rev. 1953, 92, 212. (b) Carver, T. R.; Slichter, C. P. Phys. Rev. 1956, 102, 975.

(2) Overhauser, A. W. Phys. Rev. 1953, 92, 411.

(3) Neuhaus, D.; Williamson, M. The Nuclear Overhauser Effect in Structural and Conformational Analysis; VCH Publishers: New York, 1989.

(4) Noggle, J. H.; Schirmer, R. E. The Nuclear Overhauser Effect; Academic Press: New York, 1971 